\title{
Creatine supplementation to total parenteral nutrition improves creatine status and supports greater liver and kidney protein synthesis in neonatal piglets
}

\author{
O. Chandani Dinesh ${ }^{1}$, Robert F. Bertolo ${ }^{1}$ and Janet A. Brunton ${ }^{1}$
}

BACKGROUND: Creatine is not included in commercial pediatric parenteral products; the entire creatine requirement must be met by de novo synthesis from arginine during parenteral nutrition (PN). Poor arginine status is common during $\mathrm{PN}$ in neonates, which may compromise creatine accretion. We hypothesized that creatine supplementation will improve creatine status and spare arginine in PN-fed piglets.

METHODS: Piglets (3-5-day (d) old) were provided PN with or without creatine for $14 \mathrm{~d}$. Tissue concentrations of creatine metabolites and activities of creatine-synthesizing enzymes, as well as tissue protein synthesis rates and liver lipid parameters, were measured.

RESULTS: Creatine provision lowered kidney and pancreas L-arginine:glycine amidinotransferase (AGAT, EC number 2.1.4.1) activities and plasma guanidinoacetic acid (GAA) concentration, suggesting the downregulation of de novo creatine synthesis. Creatine increased plasma creatine concentrations to sow-fed reference levels and increased the creatine concentrations in most tissues, but not in the brain. PN creatine resulted in greater protein synthesis in the liver and the kidney, but not in the pancreas, skeletal muscle, or gut. Creatine supplementation also reduced liver cholesterol concentrations, but not triglyceride or total fat.

CONCLUSION: The addition of creatine to PN may optimize the accretion of creatine and reduce the metabolic burden of creatine synthesis in rapidly growing neonates.

c reatine and creatine phosphate are amino-acid-derived compounds that are necessary to meet short-term energy requirements in tissues that have high and variable rates of energy demand. Severe creatine deficiency, as a consequence of inborn errors of creatine synthesis or transport, results in profound neurological defects, demonstrating its importance in brain development (1-4). Creatine can be acquired from the diet or synthesized endogenously as a multiorgan process. In terms of loss, creatine is subjected to continuous degradation and, in adults, it is excreted at a rate of $\sim 1.7 \mathrm{~g}$ per day (ref. 5), which represents the maintenance cost of creatine. In addition, rapidly growing neonates must accrue creatine as lean tissues expand. Factorial assessment in piglets suggests that the absolute creatine needs in growing neonates are greater than those supplied by porcine milk ( 12.7 vs. $2.8 \mathrm{mmol}$ per week, respectively); as such, neonates rely on de novo creatine synthesis (6). Creatine synthesis requires three amino acids (arginine, glycine, and methionine) and two enzymes (7). The first enzyme, L-arginine:glycine amidinotransferase (AGAT; EC number 2.1.4.1), is expressed in the kidney and pancreas, and transfers the amidino compound from arginine to glycine in order to synthesize ornithine and guanidinoacetic acid (GAA). The second enzyme, guanidinoacetate $N$-methyltransferase (GAMT; EC 2.1.1.2), methylates GAA to synthesize creatine, primarily in the liver (6). Methionine donates a methyl group via $S$ adenosylmethionine (SAM).

The growing fetus relies at least partially on the maternal supply of creatine via the placenta, but after birth the newborn must rely on endogenous synthesis $(6,8,9)$. It remains to be determined whether the prematurely born infant has the capacity to synthesize creatine effectively, particularly if a dietary creatine source is not supplied. Following preterm birth, total parenteral nutrition (PN) is often required as a means of nutritional support for infants with gastrointestinal disorders or prolonged intolerance of enteral feeding. However, creatine is not a component of pediatric PN products. In this situation, the entire creatine requirement must be met by de novo synthesis, which must create considerable demand for the amino-acid precursors, arginine and methionine. Arginine is a conditionally essential amino acid for neonates, although de novo arginine synthesis does occur in the small intestinal mucosa during first-pass metabolism, predominantly from dietary proline $(10,11,12)$. PN feeding bypasses the gut metabolism and thus causes gut atrophy; therefore, PN feeding interferes with normal arginine synthesis, and whether this affects optimal creatine accretion in the growing neonate has not yet been investigated.

The neonatal period is characterized by rapid growth and very high rates of protein synthesis to support the growth.

\footnotetext{
${ }^{1}$ Department of Biochemistry, Memorial University of Newfoundland, St John's, Newfoundland and Labrador, Canada. Correspondence: Janet A. Brunton (jbrunton@mun.ca) Received 1 March 2017; accepted 21 August 2017; advance online publication 27 September 2017. doi:10.1038/pr.2017.208
} 
Compromised de novo arginine synthesis during PN feeding, as well as an increased demand for arginine to support creatine synthesis, may limit arginine availability for protein synthesis. Alternatively, the sparing of arginine through the provision of preformed creatine in $\mathrm{PN}$ may lead to enhanced protein synthesis in growing neonates. We hypothesized that the addition of creatine to $\mathrm{PN}$ would reduce the need for de novo creatine synthesis and spare arginine for protein synthesis in a PN-fed piglet model.

\section{METHODS}

\section{Animals, Surgical Procedure, and Daily Care}

All procedures were approved by the Institutional Animal Care Committee of Memorial University of Newfoundland (St John's, Canada) and conformed to the guidelines of the Canadian Council on Animal Care. Fourteen Yucatan miniature piglets (3-5days old) were obtained from the breeding herd (Animal Care Services, Memorial University of Newfoundland) as littermate pairs. The animals immediately underwent surgical implantation of two silastic venous catheters (jugular and femoral) under general anesthesia. Detailed descriptions of the surgical procedure and post-surgical care were published elsewhere (13). Immediately following surgery, the piglets were housed individually in metabolic cages with a single-port swivel and a tether system (Lomir Biomedical, Notre-Dame-de-l'îlePerrot, QC, Canada) that facilitates continuous PN feeding while allowing the piglets to move freely. The piglets were weighed each morning and diet infusion rates were adjusted daily according to the piglet body weight. Five additional piglets were identified in the herd but were left with the sow until the end of the study. These piglets were of similar age to the catheterized piglets, but were not littermates.

\section{Diet Regimen}

Piglets were randomized to either creatine-supplemented PN (Creatine) or creatine-free PN (Control). Intravenous diets were provided as continuous infusions; $\mathrm{PN}$ was initiated immediately following surgery at $50 \%$ of the target rate, and then increased to $75 \%$ on the following morning and to $100 \%$ of the target rate $(13.5 \mathrm{ml} / \mathrm{kg} /$ d) on the evening of day 1 . Both diets provided similar amounts of the total amino acids (Sigma-Aldrich, Oakville, ON, Canada; Supplementary Table S1 online). Vitamins, iron dextran, minerals, and trace elements were added to each diet just before feeding (Supplementary Table S2), along with Intralipid 20\% (52 ml/kg/d), as previously described (13). Creatine-supplemented piglets received $0.12 \mathrm{~g} / \mathrm{kg} / \mathrm{d}(0.79 \mathrm{mmol} / \mathrm{kg} / \mathrm{d})$ creatine as creatine monohydrate (Sigma-Aldrich). This concentration satisfied the piglets' total whole-body creatine accretion and maintenance based on previous work in 4-11-day-old, sow-fed (SF) neonatal piglets (6). The diets provided $0.94 \mathrm{~g}$ of arginine $/ \mathrm{kg} / \mathrm{d}$, which is considered as a moderate arginine intake (14). Piglets were maintained on the same PN for 14 days.

\section{Necropsy Procedure}

After 14 days, a flooding dose of L-phenylalanine $(1.5 \mathrm{mmol}$ per $\mathrm{kg}$ of body weight; Sigma-Aldrich) containing $0.15 \mathrm{mmol}$ per $\mathrm{kg}$ of body weight and L-[ring- ${ }^{2} \mathrm{H}_{5}$ ] phenylalanine (Cambridge Isotopes, Tewksbury, MA) was administrated into the jugular vein to measure tissuespecific fractional rates of protein synthesis. Phenylalanine (labeled and unlabeled) was dissolved in pyrogen-free water $(11 \mathrm{ml}$ per $\mathrm{kg}$ of body weight) and warmed before administering. Thirty minutes after dosing, the piglets were anesthetized with halothane and were delivered with oxygen by a mask. Tissues including the whole right kidney and the pancreas were frozen in liquid nitrogen and stored at $-80^{\circ} \mathrm{C}$ for later analyses of AGAT activity, creatine, and GAA concentrations. Samples of brain, skeletal muscle, and liver were also removed and frozen for the analysis of creatine and GAA concentrations. Small intestinal mucosa, liver, and skeletal muscle samples were taken to analyze the rates of protein synthesis. The five SF piglets underwent the same necropsy protocol for the purpose of establishing SF reference data.

\section{GAA and Creatine Analyses}

Tissue (kidneys, pancreas, brain, and the liver) and plasma GAA and creatine concentrations were assayed using an high-performance liquid chromatography (HPLC) method modified from Buchberger and Ferdig (15) using a C18 reverse-phase column (Hypersil ODS $5 \mathrm{U} 150 \times 4.6 \mathrm{~mm}$ column) with ninhydrin (Sigma-Aldrich) derivatization and fluorescence detection (Ex/EM 390/470).

\section{Skeletal Muscle Creatine Concentrations}

Creatine concentration of the gastrocnemius muscle was determined using the simplified method of Lamarre et al. (9). Tissues were homogenized in a $50 \mathrm{mmol} / \mathrm{l}$ Tris buffer ( $\mathrm{pH}$ 7.4) and kept for $30 \mathrm{~min}$ at room temperature to convert phosphocreatine into free creatine. The homogenates were then deproteinized with trifluoroacetic acid in methanol and microcentrifuged at $13,500 \mathrm{~g}$ for $10 \mathrm{~min}$. Creatine was eluted with an isocratic mobile phase of $0.1 \%$ trifluoroacetic acid and 3\% methanol in an N/RP-HPLC Hypercarb $100 \times 4.6 \mathrm{~mm}$ column with UV detection at $210 \mathrm{~nm}$. The total creatine concentrations were determined by reference to a standard curve that was run with the samples.

\section{AGAT Assay}

AGAT activity was assayed using a modified method of Van et al. (16). The assay measured the amount of ornithine converted from arginine because of AGAT activity (transamidinase). The whole kidney was pulverized and a representative sample was used to measure the activity of transamidinase. Supernatants prepared from homogenized frozen kidney or pancreas samples were incubated at $37^{\circ} \mathrm{C}$ in a shaking water bath with different substrate buffers containing either arginine or glycine or arginine and glycine or phosphate buffer with no substrates. The resulting supernatants were incubated in a $92{ }^{\circ} \mathrm{C}$ water bath with ninhydrin color reagent dissolved in anhydrous 1-propanol (Sigma-Aldrich). The absorbance of the final incubations was read at $505 \mathrm{~nm}$ in a spectrophotometer. The protein content of the homogenates was assayed using the Pierce BCA protein assay kit (Thermo Fisher Scientific, Mississauga, ON, Canada). Ornithine produced by AGAT was presented as nmol of ornithine per $\mathrm{mg}$ of protein per min.

\section{GAMT Assay}

GAMT activity was assayed, as described previously by da Silva et al. (17), which was modified from Ogawa et al. (18). Reactions, stop reactions, and blanks were prepared from fresh liver samples immediately following necropsy and were frozen at $-80^{\circ} \mathrm{C}$ for later analysis. Creatine synthesized by GAMT activity was measured via HPLC and ninhydrin derivatization (15) and activity was expressed per $\mathrm{mg}$ of protein per min.

\section{Tissue-Specific Protein Synthesis}

A $100 \mathrm{mg}$ sample of a frozen tissue was homogenized and prepared for the extraction of phenylalanine, as per the method of Lamarre et al. (19). Both the tissue-free and hydrolyzed protein fractions were applied to a hydrophobic solid-phase extraction cartridge (Bond Elute C18, 100 mg, $1 \mathrm{ml}$; Agilent Technologies, Santa Clara, CA). The eluent was dried overnight and resuspended in $80 \mu \mathrm{l}$ of HPLC water for the derivatization. The isotopic enrichment of $\mathrm{L}$-[ring- $\left.{ }^{2} \mathrm{H}_{5}\right]$ phenylalanine in tissue-free and protein-bound fractions was determined by gas chromatography-mass spectrometry and pentafluorobenzyl bromide (PFBBr) derivative (Sigma-Aldrich) with a model 6890 GC linked to a $5976 \mathrm{~N}$ quadrupole MS (Agilent Technologies) operating in the electron ionization mode (19). A mixed sample of L-[ring $\left.{ }^{2} \mathrm{H}_{5}\right]$ phenylalanine and unlabeled phenylalanine was run in the scan mode, in which 91 and 96 ions or 300 and 305 were identified as potential ions. A standard curve was run before analyzing the samples to identify the linear ranges. Ions with a 
mass-to-charge ratio of 91 and 96 ions were monitored via selectedion monitoring for the liver, small intestinal mucosa, and muscle tissues; for kidney and pancreas samples, 300 and 305 ions were monitored. Percent molar enrichment ( $\mathrm{mol} \%)$ was determined, and the fractional synthesis rate $(\% / d)$ of protein was calculated as follows:

$$
\mathrm{FSR}=\mathrm{IE}_{\text {bound }} / \mathrm{IE}_{\text {free }} \cdot 1,440^{\prime} / t \cdot 100
$$

where $\mathrm{IE}_{\text {bound }}$ and $\mathrm{IE}_{\text {free }}$ are the isotopic enrichments (mol\%) of $\mathrm{L}$-[ring- ${ }^{2} \mathrm{H}_{5}$ ] phenylalanine of the perchloric acid-insoluble (proteinbound) and perchloric acid-soluble (tissue-free) phenylalanine pool; $t$ is the time of labeling in $\mathrm{min}$; and 1,440 is the number of minutes per day.

\section{Plasma and Tissue-Free Amino Acids}

Tissues were homogenized as previously described (20). Plasma- and tissue-free amino-acid concentrations were measured with reversephase HPLC (C18 column), following the derivatization with phenylisothiocyanate (Waters, Woburn, MA), as per the method of Bidlingmeyer et al. (21).

Liver Lipids and Plasma Cholesterol and Triglyceride Analyses Lipid was extracted using the method of Folch et al. (22). Extracted lipid from triplicate liver samples was dried under nitrogen gas and weighed to quantify the lipid content. Extracted lipid was also used to analyze hepatic cholesterol and triglyceride (TG) concentrations via spectrophotometer assays (505 and $520 \mathrm{~nm}$, respectively) using commercially available kits (Genzyme DC-CAL, Triglyceride-SL, and Cholesterol-SL) from Sekisui Diagnostic (Charlottetown, PE, Canada). Plasma samples were also analyzed via spectrophotometer assays (505 and $520 \mathrm{~nm}$, respectively) using a commercially available glycerol standard (Sigma-Aldrich) and cholesterol standard (Pointe Scientific, Canton, MI), and the same commercial kits were used for liver samples (Triglyceride-SL and Cholesterol-SL, Sekisui Diagnostic).

\section{Statistical Analysis}

The data were analyzed using two-tailed paired $t$-tests (GraphPad 5, Graph Pad Software, La Jolla, CA), and were considered significantly different if $P<0.05$. The data are expressed as means \pm SD. Data collected from the SF reference group were used for reference only and were not included in the statistical analyses, as this group was not treated identically to the treatment groups (i.e., no surgical or flooding-dose procedures). SF reference group means \pm SD are presented for comparison purposes.

\section{RESULTS}

The growth rates of the piglets in the two treatment groups were not significantly different.

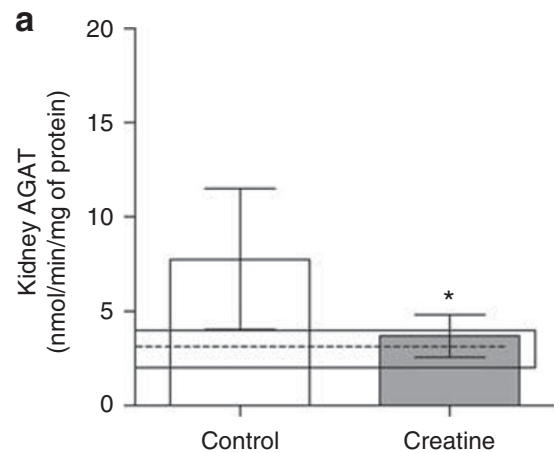

\section{Enzyme Activities}

Creatine supplementation to PN downregulated the kidney AGAT activity by $52 \%(P=0.05)$ and pancreas AGAT activity by $39 \%(P=0.002)$ compared with the Control group (Figure 1). The mean kidney AGAT activity in the Creatine animals fell within the mean $\pm S D$ measured in the agematched SF piglets, whereas the mean for the Control piglets was $\sim 139 \%$ above the SF mean. Similarly, pancreatic AGAT activity in the Creatine group was within the SF reference mean $\pm \mathrm{SD}$, whereas the Control group pancreatic AGAT activity was $40 \%$ higher than the SF reference mean (Figure 1). Creatine supplementation did not affect the liver GAMT activity, and both mean PN values were $~ 55 \%$ below the SF reference mean. The liver GAMT activity in the SF piglets was quite variable (Figure 2).

\section{Tissue GAA and Creatine Concentrations}

GAA concentrations in the kidney, pancreas, liver, and the brain did not differ between treatment groups (Table 1). The

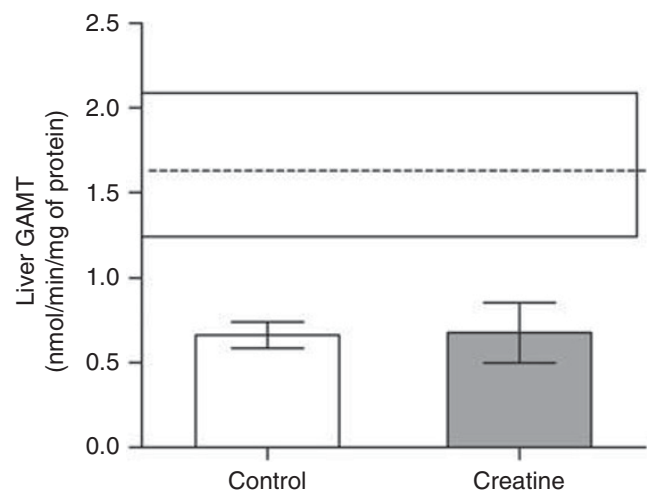

Figure 2. GAMT enzyme activity in the liver. Open bars: control group, $n=7$; gray bars: creatine group, $n=7$. The values are expressed as means $\pm S D$. The broken line and the box represent the mean $\pm S D$, derived from a group of sow-fed reference piglets $(n=5)$ that were not littermates to the treatment groups. GAMT, guanidinoacetate $N$ methyltransferase.

b

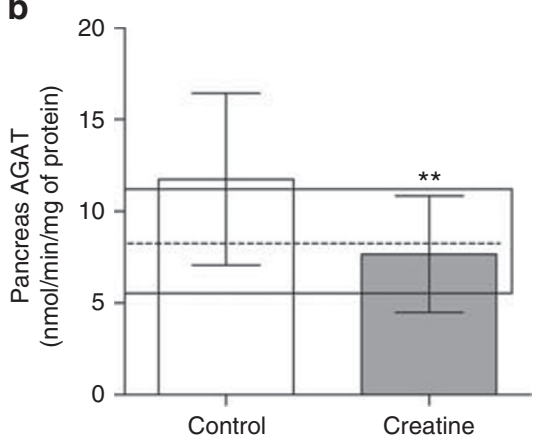

Figure 1. AGAT enzyme activity in kidney and pancreas tissues. (a) kidney and (b) pancreas. Open bars: control group, $n=7$; gray bars: creatine group, $n=7$. The values are expressed as means \pm SD ${ }^{*} P<0.01$ and ${ }^{*} P<0.05$ by a paired $t$-test. The broken line and the box represent the mean \pm SD derived from a group of sow-fed reference piglets $(n=5)$ that were not littermates to the treatment groups. AGAT, L-arginine:glycine amidinotransferase. 
Table 1. Tissue and plasma GAA concentrations in piglets given control vs. creatine $\mathrm{PN}^{\mathrm{a}}$

\begin{tabular}{|c|c|c|c|}
\hline & Control & Creatine & $\mathrm{SF}^{\mathrm{b}}$ \\
\hline \multicolumn{4}{|c|}{$\mathrm{nmol} / \mathrm{g}$} \\
\hline Kidney & $435 \pm 234$ & $376 \pm 206$ & $480 \pm 123$ \\
\hline Pancreas & $240 \pm 185$ & $271 \pm 170$ & $268 \pm 107$ \\
\hline Liver & $60 \pm 10$ & $68 \pm 29$ & $97 \pm 50$ \\
\hline Brain & $64 \pm 14$ & $62 \pm 15$ & $79 \pm 33$ \\
\hline Plasma ( $\mu \mathrm{mol} / \mathrm{l})$ & $15.2 \pm 5.0$ & $8.3 \pm 2.2^{* *}$ & $6.0 \pm 1.2$ \\
\hline \multicolumn{4}{|c|}{$\begin{array}{l}\text { GAA, guanidinoacetic acid; PN, parenteral nutrition; SF, sow-fed. } \\
\text { The asterisk indicates different from Control. }{ }^{*} P=0.01 \text { by a paired } t \text {-test. } \\
\text { aValues are means } \pm \text { SD; } n=7 \text { per group for PN treatments except for plasma, } \\
\text { where } n=6 \text {. } \\
\text { bSF }(n=5) \text { data were derived from a group of sow-fed piglets that were not litter- } \\
\text { mates to the PN groups; SF data were not included in the statistical analyses. }\end{array}$} \\
\hline
\end{tabular}

Table 2. Tissue and plasma creatine concentrations in piglets given Control vs. Creatine $\mathrm{PN}^{\mathrm{a}}$

\begin{tabular}{|c|c|c|c|}
\hline & Control & Creatine & $\mathrm{SF}^{\mathrm{b}}$ \\
\hline \multicolumn{4}{|c|}{$\mu \mathrm{mol} / \mathrm{g}$} \\
\hline Kidney & $1.2 \pm 0.6$ & $2.5 \pm 0.7^{* *}$ & $1.8 \pm 0.5$ \\
\hline Pancreas & $1.0 \pm 0.4$ & $2.3 \pm 0.8^{* *}$ & $1.4 \pm 0.4$ \\
\hline Liver & $1.1 \pm 0.7$ & $2.2 \pm 1.5^{*}$ & $1.1 \pm 0.2$ \\
\hline Skeletal muscle ${ }^{c}$ & $22 \pm 3.0$ & $26 \pm 2.6^{*}$ & $25 \pm 5.0$ \\
\hline Brain & $9.8 \pm 3.1$ & $10.1 \pm 1.5$ & $8.2 \pm 2.1$ \\
\hline Plasma ( $\mu \mathrm{mol} / \mathrm{l})$ & $54 \pm 21$ & $232 \pm 46^{* * *}$ & $249 \pm 40$ \\
\hline \multicolumn{4}{|c|}{$\begin{array}{l}\text { PN, parenteral nutrition; SF, sow-fed. } \\
\text { aValues are means } \pm S D ; n=7 \text { per group for PN treatments except for plasma, } \\
\text { where } n=6 \text {. } \\
\text { }{ }^{\circ} \mathrm{SF}(n=5) \text { data were derived from a group of } S F \text { piglets that were not littermates } \\
\text { to the PN groups; SF data were not included in the statistical analyses. } \\
\text { 'Total creatine. } \\
\text { Asterisks indicate different from Control, }{ }^{* *} P \leq 0.01 \text { and }{ }^{*} P<0.05 \text { by a paired } t \text {-test. }\end{array}$} \\
\hline
\end{tabular}

kidney and pancreas GAA concentrations were highly variable in both treatment groups (Table 1). GAA concentrations were comparable to SF reference piglets for most tissues, except the liver where the mean concentration in the SF group was approximately twice that of the experimental piglets (Table 1). Creatine supplementation resulted in significantly higher creatine concentrations in the kidney, pancreas, and liver compared with the Control group (Table 2). Total creatine content (i.e., creatine and phosphocreatine) in the skeletal muscle was significantly higher in the Creatine compared with the Control group. SF pigs tended to have creatine concentrations between those of the treatment groups for most tissues. Lack of creatine in Control piglets did not alter GAA (Table 1) or creatine (Table 2) concentrations in the brain. Furthermore, the mean brain GAA and creatine concentrations measured in both Creatine and Control groups were within the SF reference range (Tables 1 and 2).
Plasma GAA, Creatine, and Amino-Acid Concentrations Creatine supplementation resulted in a significantly lower plasma GAA concentration (Table 1), but in a higher creatine concentration (Table 2) compared with Control pigs. Creatine supplementation to PN resulted in plasma GAA and creatine concentrations that were similar to SF reference pigs, whereas the omission of creatine for Control pigs reduced plasma GAA by $50 \%$ and plasma creatine by $80 \%$ compared with the mean values in SF pigs. Amino-acid concentrations were similar between Creatine and Control groups, with the exception of proline, which tended to be higher in the Control pigs $(P=0.06$; Supplementary Table S3).

\section{Tissue-Specific Fractional Protein Synthesis Rates}

Liver and kidney fractional protein synthesis rates were significantly higher in Creatine piglets compared with those in the Control group (Figure 3). There were no differences in protein synthesis rates in the pancreas, small intestinal mucosa, or skeletal muscle between experimental groups (Figure 3).

\section{Tissue-Free Amino-Acid Concentrations}

No differences in free amino-acid concentrations between treatments were found in the liver or kidney tissues (Supplementary Tables S4 and S5).

\section{Liver Weight, Liver Lipid, TG, and Cholesterol}

Liver cholesterol in the Creatine piglets was significantly lower than in the Control group (Table 3). However, the TG concentration, total lipid, or liver weights were not different between the groups. Regardless of the treatment, both PN-fed groups had liver weights, liver lipid concentrations, and liver TG concentrations that were 1.7-2.5 times higher than the SF reference ranges. Plasma cholesterol and TG were not different between the treatment groups. However, the mean cholesterol SF value was approximately two times higher than that of the PN-treated piglets. The mean plasma TG concentrations measured in the two $\mathrm{PN}$-treated groups were within the range of values measured in the SF piglets (Table 3).

\section{DISCUSSION}

Previously, we demonstrated that suckling neonatal piglets cannot meet creatine requirements from milk alone, and that $75 \%$ of creatine needs must come from endogenous synthesis from arginine and methionine (6). Although methionine is required for creatine synthesis, it was provided in PN at $20 \%$ over requirement, and, therefore, it was likely not considered to be limiting. In $\mathrm{PN}$-fed piglets, arginine synthesis is diminished with gut atrophy (10), and we demonstrated that tissue creatine concentrations were proportionate to the intravenous arginine delivery (unpublished data), suggesting that the availability of arginine limited de novo creatine synthesis. In this study, we hypothesized that the addition of creatine to PN would spare arginine for protein synthesis. Indeed, an important finding is that liver and kidney protein 

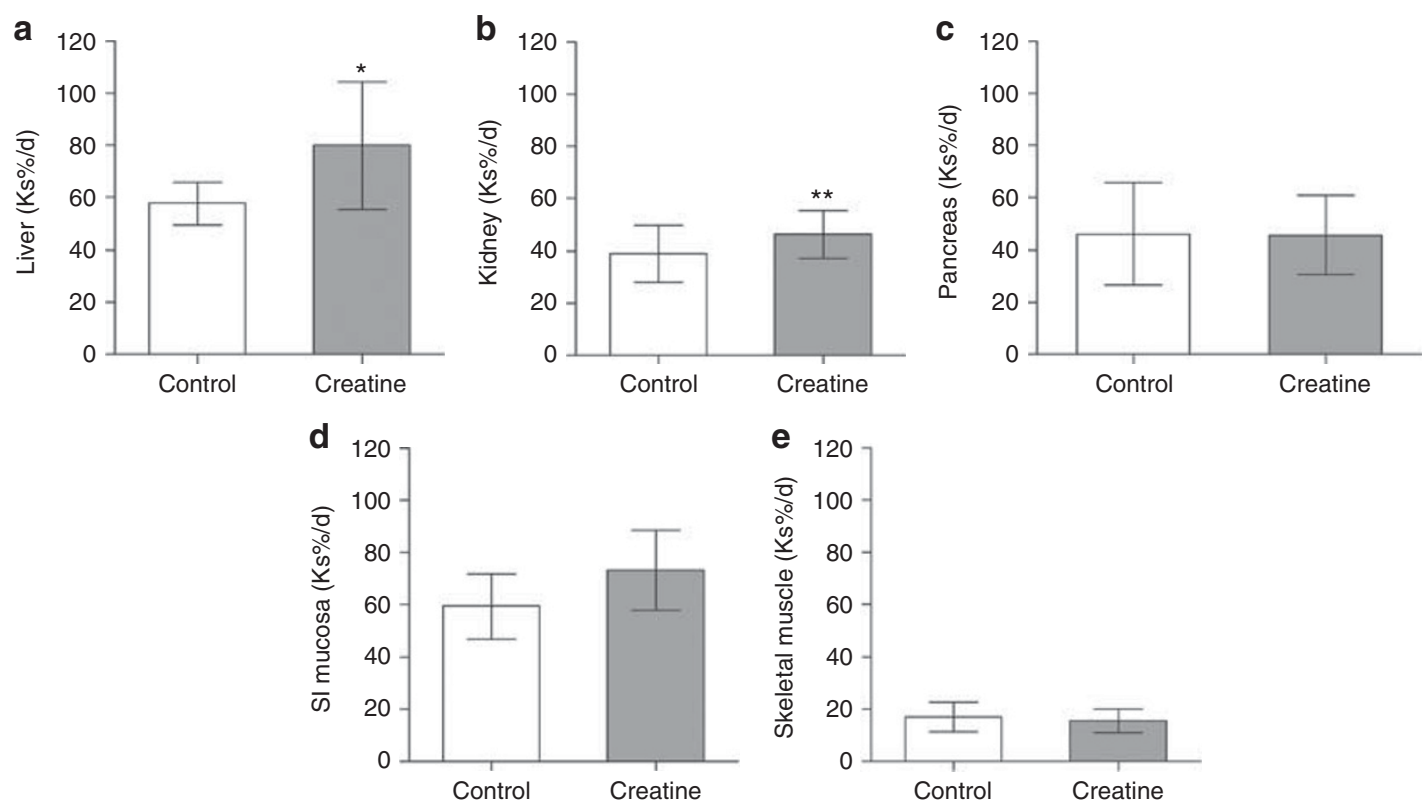

Figure 3. Tissue-specific rates of protein synthesis. (a) the liver, (b) kidneys, (c) pancreas, (d) small intestinal mucosa, and (e) in the skeletal muscle. Open bars: control group; gray bars: creatine group, where $n=7$ per group except for the kidney, where $n=6$ and pancreas, where $n=5$. The values are expressed as means $\pm \mathrm{SD}{ }^{*} P=0.01$ and ${ }^{*} P<0.05$ by a paired $t$-test. $\mathrm{Sl}$, small intestine.

Table 3. Body and liver weights, liver, and plasma lipid concentrations at necropsy in piglets given Control vs. Creatine $\mathrm{PN}^{\mathrm{a}}$

\begin{tabular}{lrrr}
\hline & Control & Creatine & $\mathrm{SF}^{\mathrm{b}}$ \\
\hline BW (kg) & $3.6 \pm 0.4$ & $3.6 \pm 0.6$ & $3.7 \pm 0.2$ \\
Liver weight (g/kg BW) & $52 \pm 6.4$ & $55 \pm 8.4$ & $32 \pm 2.3$
\end{tabular}

\section{Whole liver}

$\begin{array}{lccc}\text { Lipid }(\mathrm{g} / \mathrm{kg} \mathrm{BW}) & 2.0 \pm 0.4 & 2.3 \pm 0.6 & 1.0 \pm 0.1 \\ \text { Triglyceride }(\mu \mathrm{mol} / \mathrm{kg} \mathrm{BW}) & 407 \pm 259 & 351 \pm 164 & 166 \pm 81 \\ \text { Cholesterol }(\mu \mathrm{mol} / \mathrm{kg} \mathrm{BW}) & 372 \pm 151 & 151 \pm 73^{* *} & 146 \pm 56\end{array}$

Plasma

Triglyceride $(\mu \mathrm{mol} / \mathrm{ml}) \quad 0.31 \pm 0.01 \quad 0.29 \pm 0.10 \quad 0.43 \pm 0.13$

Cholesterol $(\mu \mathrm{mol} / \mathrm{ml}) \quad 2.3 \pm 0.7 \quad 2.2 \pm 0.7 \quad 4.4 \pm 1.9$

BW, body weight; PN, parenteral nutrition; SF, sow fed.

Values are means $\pm S D ; n=7$ for PN treatments.

${ }^{\mathrm{b}} \mathrm{SF}(n=5)$ data were derived from a group of SF piglets that were not littermates to the PN groups; SF data were not included in the statistical analyses.

The asterisk indicates different from Control. $P<0.01$ by a paired $t$-test.

synthesis was higher with creatine supplementation. However, there was no difference in muscle protein synthesis.

The concentration of arginine supplied in the PN diet was designed to be lower than that necessary to maximize protein synthesis in the muscle (14) to allow spared arginine to affect muscle protein synthesis; however, the amount of arginine spared by creatine was not conveyed to the muscle. In the liver, the enhanced protein synthesis may be due to greater arginine availability, but this was not demonstrated by liver- free arginine concentrations, which were not different between the treatment groups. A similar situation occurred in the kidney, with greater protein synthesis but no difference in free arginine concentrations. However, free concentrations are not necessarily reflective of arginine availability; it may be that arginine turnover was more rapid in the Creatine group, directing more arginine toward protein synthesis without changing the free concentrations. This possibility could be clarified with a tracer study to quantify arginine flux rates. Alternatively, creatine may increase tissue protein synthesis via the mechanisms unrelated to arginine. In vitro and in vivo studies have identified a number of mechanisms by which creatine stimulates protein synthesis in the muscle. Myogenic cells in culture exposed to oxidative stress have diminished proliferation and differentiation, and creatine attenuated these effects (23). Creatine also upregulates the expression of a number of trophic factors in the muscle, including IGF-1, which can stimulate protein synthesis through the activation of mTOR pathway intermediates (24). To our knowledge, none of these mechanisms related to creatine have been studied in the liver or the kidney. The lack of response to creatine in muscle may have been due to the limited aminoacid substrate in that tissue, or due to the relatively low dose of creatine used in this study compared with human supplementation trials.

Skeletal muscle contains over $95 \%$ of the total body creatine, with one-third as the free form and the rest of it as phosphorylated creatine (25). Creatine kinase activity is found in the cytoplasm of several tissues, including the skeletal muscle, cardiac muscle, and the brain. We hypothesized that 2 weeks of creatine supplementation to PN would 


\section{Articles | Dinesh et al.}

increase skeletal muscle and brain creatine concentrations. Interestingly, the skeletal muscle total creatine concentration was higher in our creatine-fed piglets; however, we found no difference in the brain creatine concentrations, and both groups were similar to SF reference piglets. The brain creatine pool is relatively small compared with the creatine stored in the muscle, representing less than $5 \%$ of the entire body pool. However, adequate brain creatine must be of physiological importance, as profound negative neurodevelopmental effects have been reported secondary to inborn errors of creatine synthesis or transport (26); thus, creatine is critical to normal neurological developmental processes in neonates. Previously, we reported that the brain AGAT activity was not detected, and GAMT activity was very low in neonatal piglets (6). In this study, there was a low ratio of GAA to creatine in brain tissues compared with major GAA and creatine-synthesizing organs, which suggests that the brain's capacity to synthesize its own GAA seems unlikely, and accretion likely depends on peripheral de novo synthesis (27). The mean plasma creatine concentration was $80 \%$ lower in piglets, given the creatinefree PN compared with the Creatine and SF reference piglets; as such, perhaps, the brain has a priority for circulating creatine, even in the situation of low-plasma creatine during PN. Alternatively, it may be that the brain creatine pool was not measurably affected during the short-term use of creatinefree PN. SF neonatal piglets studied at 4 and 11 days of age had $50 \%$ greater body weight at the older age, but no change in the brain weight or brain creatine concentration (6); therefore, unlike the muscle, the brain does not have the same need for rapid creatine accretion and might be less sensitive to dietary supply. The rate of creatine degradation in the neonatal brain is also unknown but is likely very slow. In infants with AGAT deficiency, neurological symptoms do not become apparent until the second year of life (26). Thus, brain creatine likely degrades too slowly to create a deficit after only 14 days of creatine-free PN.

With the addition of dietary creatine, downregulation of creatine synthesis was evident by a lower AGAT activity in the kidney and pancreas, as well as by lower GAA concentrations in plasma. AGAT has been demonstrated as the rate-limiting step in creatine biosynthesis in humans (28) and in rodents $(7,17,29,30)$ as creatine feeding induced a lower AGAT activity with no change in the liver GAMT activity. Similarly, in our piglets, the AGAT activity was affected with a dietary supply of creatine, and the liver GAMT activity did not change. Therefore, it appears that creatine synthesis is regulated at the level of AGAT in neonatal piglets as well.

The kidney has been identified as the major organ responsible for GAA synthesis in rodents (5). Interestingly, in piglets, we measured pancreatic AGAT-specific activity that was $53-159 \%$ higher (per gram of protein) than that measured in the kidney. However, considering that piglet kidneys are approximately four times the mass of the pancreas (6), the kidneys are likely still the organ responsible for the most of endogenous GAA synthesis in neonatal piglets. Although the pancreas has a higher AGAT-specific activity than the kidney, its GAMT-specific activity is relatively low (i.e., only $\sim 25 \%$ that of the liver) (6), suggesting that the pancreas has a net release of GAA with a minimal net release of creatine into portal blood. Therefore, the high pancreatic AGAT-specific activity may contribute some GAA directly to the liver for creatine synthesis, although this requires confirmation.

Because prolonged PN can lead to hepatic fat accumulation and $\mathrm{PN}$-associated liver disease (31), we also measured lipid parameters in the liver as a secondary objective. As expected, the PN-fed groups had a higher liver lipid content and heavier livers compared with those of SF piglets of the same age. Lipid accumulation in the liver has been associated with impaired methionine metabolism (32). Both phosphatidyl choline (PC) and creatine synthesis require hepatic methylation reactions, which rely on an adequate methionine pool to serve as a methyl donor. Moreover, adequate PC synthesis is required for very low density lipoprotein assembly and secretion of lipids from the liver. It is possible that creatine supplementation might spare methionine for transmethylation to PC, thereby reducing liver lipids in this $\mathrm{PN}$-fed model. We found that creatine supplementation lowered the total liver cholesterol concentration, but no differences in liver weight or TG concentration were detected. While creatine supplementation may have enhanced PC synthesis, allowing for more efficient transport of cholesterol out of the liver, it is unclear why total lipids or TGs were also not measurably reduced. In rodents fed with a high-fat diet, creatine supplementation led to a profound reduction in lipid accumulation in the liver (33), but creatine was provided in the diet at almost 30 times the concentration delivered in our PN. It is tempting to speculate that creatine has a role in ameliorating $\mathrm{PN}$-induced liver steatosis, but more research is needed on lipid metabolism outcomes.

To our knowledge, this is the first time that creatine has been studied as a supplement to PN for use in neonates. Our data suggest that the requirement for creatine synthesis might be a burden on other arginine metabolic pathways. The addition of creatine to PN appears to be necessary to support optimal creatine accretion, and liver and kidney protein synthesis in rapidly growing neonates.

\section{SUPPLEMENTARY MATERIAL}

Supplementary material is linked to the online version of the paper at http://www.nature.com/pr

\section{ACKNOWLEDGMENTS}

We thank ME Dodge for her assistance in the surgeries. O.C.D., J.A.B., and R. F.B. designed the research; O.C.D., J.A.B., and R.F.B conducted the research; O.C.D. analyzed the data; and O.C.D. drafted the paper. J.A.B. and R.F.B. reviewed and revised the paper. O.C.D., J.A.B., and R.F.B. had a primary responsibility for the final content. All the authors read and approved the final manuscript.

\section{STATEMENT OF FINANCIAL SUPPORT}

This research was funded by a Janeway Children's Hospital Foundation Research Award and was supported by the Janeway Children's Hospital Foundation Research Grant. 
Disclosure: The authors declare no conflict of interest.

\section{REFERENCES}

1. Leuzzi V, Bianchi MC, Tosetti M, et al. Brain creatine depletion: guanidinoacetate methyltransferase deficiency (improving with creatine supplementation). Neurology 2000;55:1407-9.

2. Battini R, Leuzzi V, Carducci C, et al. Creatine depletion in a new case with AGAT deficiency: clinical and genetic study in a large pedigree. Mol Genet Metab 2002;77:326-1.

3. deGrauw TJ, Salomons GS, Cecil KM, et al. Congenital creatine transporter deficiency. Neuropediatrics 2002;33:232-8.

4. Royes LF, Fighera MR, Furian AF, et al. Effectiveness of creatine monohydrate on seizures and oxidative damage induced by methylmalonate. Pharmacol Biochem Behav 2006;83:136-44.

5. Wyss M, Kaddurah-Daouk R. Creatine and creatinine metabolism. Physiol Rev 2000;80:1107-213

6. Brosnan JT, Wijekoon EP, Warford-Woolgar L, et al. Ceatine synthesis is a major metabolic process in neonatal piglets and has important implications for amino acids metabolism and methyl balance. J Nutr 2009;139:1292-7

7. Walker JB. Creatine: biosynthesis, regulation and function. Adv Enzymol Relat Areas Mol Biol 1979;50:177-242.

8. Ireland Z, Russell AP, Wallimann T, Walker DW, Snow R. Developmental changes in the expression of creatine synthesizing enzymes and creatine transporter in a precocial rodent, the spiny mouse. BMC Dev Biol 2009;9:39.

9. Lamarre SG, Edison EE, Wijekoon EP, Brosnan ME, Brosnan JT. Suckling rat pups accumulate creatine primarily via de novo synthesis rather than from dam milk. J Nutr 2010;140:1570-3.

10. Brunton JA, Bertolo RF, Pencharz PB, Ball RO. Proline ameliorates arginine deficiency during enteral but not parenteral feeding in neonatal piglets. Am J Physiol 1999;277:E223-31.

11. Bertolo RF, Brunton JA, Pencharz PB, Ball RO. Arginine, ornithine, and proline interconversion is dependent on small intestinal metabolism in neonatal pigs. Am J Physiol Endocrinol Metab 2003;284:E915-22.

12. Wilkinson DL, Bertolo RF, Brunton JA, Shoveller AK, Pencharz PB, Ball RO. Arginine synthesis is regulated by dietary arginine intake in the enterally fed neonatal piglet. Am J Physiol Endocrinol Metab 2004;287: E454-62.

13. Brunton JA, Baldwin MP, Hanna RA, Bertolo RF. Proline supplementation to parenteral nutrition results in greater rates of protein synthesis in the muscle, skin, and small intestine in neonatal Yucatan miniature piglets. J Nutr 2012;142:1004-8.

14. Brunton JA, Bertolo RF, Pencharz PB, Ball RO. Neonatal piglets with small intestinal atrophy fed arginine at concentration 100 to $300 \%$ of NRC were arginine deficient. In: RO. Ball, ed. Proceedings of the 9th International Symposium on Digestive Physiology in Pigs, Banff: Short communications, vol. 2. Alberta, Canada: University of Alberta, 2013:210-2.

15. Buchberger W, Ferdig M. Improved high-performance liquid chromatographic determination of guanidino compounds by pre-column derivatization with ninhydrin and fluorescence detection. J Sep Sci 2004;27:1309-2.
16. Van Pilsum JF, Taylor D, Zakis B, McCormick P. Simplified assay for transamidinase activities of rat kidney homogenates. Anal Biochem 1970;35:277-86.

17. da Silva RP, Nissim I, Brosnan ME, Brosnan JT. Creatine synthesis: hepatic metabolism of guanidinoacetate and creatine in the rat in vitro and in vivo. Am J Physiol Endocrinol Metab 2009;296:E256-61.

18. Ogawa H, Ishiguro Y, Fujioka M. Guanidinoacetate methytransferase from rat liver: purification, properties, and evidence for the involvement of sulfhydryl groups for activity. Arch Biochem Biophys 1983;226:265-75.

19. Lamarre SG, Saulnier RJ, Blier PU, Driedzic WR. A rapid and convenient method for measuring the fractional rate of protein synthesis in ectothermic animal tissues using a stable isotope tracer. Comp Biochem physiol B Biochem Mol Biol 2015;182:1-5.

20. Nichols NL, Bertolo RF. Luminal threonine concentration acutely affects intestinal mucosal protein and mucin synthesis in piglets. $\mathrm{J}$ Nutr. 2008;138:1298-303.

21. Bidlingmeyer BA, Cohen SA, Tarvin TL. Rapid analysis of amino acids using pre-column derivatization. J Chromatogr 1984;336:93-104.

22. Folch J, Lees M, Sloane Stanley GH. A simple method for the isolation and purification of total lipids from animal tissues. J Biol Chem 1957;226: 497-509.

23. Sestili P, Barbieri E, Martinelli C, et al. Creatine supplementation prevents the inhibition of myogenic differentiation in oxidatively injured $\mathrm{C} 2 \mathrm{C} 12$ murine myoblasts. Mol Nutr Food Res 2009;53:1187-204.

24. Sestili P, Ambrogini P, Barbieri E, et al. New insights into the trophic and cytoprotective effects of creatine in in vitro and in vivo models of cell maturation. Amino Acids 2016;48:1897-911.

25. Balsom PD, Soderlund K, Ekblom B. Creatine in humans with special reference to creatine supplementation. Sports Med 1974;18:268-80.

26. Mercimek-Mahmutoglu S, Salomons GS. Creatine deficiency syndromes. In: Pagon RA et al., eds. GeneReviews. Seattle, WA: University of Washington, 2009;1993-2016.

27. Hanna-El-Daher L, Braissant O. Creatine synthesis and exchanges between brain cells: what can be learned from human creatine deficiencies and various experimental models? Amino Acids 2016;48:1877-95.

28. Derave W, Marescau B, Vanden Eede E, Eijnde BO, De Deyn PP, Hespel P. Plasma guanidino compounds are altered by oral creatine supplementation in healthy humans. J Appl Physiol 2004;7:852-7.

29. McGuire DM, Gross MD, Van Pilsum JF, Towle HC. Repression of rat kidney L-arginine:glycineamidinotransferase synthesis by creatine at a pretranslational level. J Biol Chem 1984;259:12034-8.

30. da Silva RP, Clow K, Brosnan JT, Brosnan ME. Synthesis of guanidinoacetate and creatine from amino acids by rat pancreas. $\mathrm{Br} \mathrm{J}$ Nutr 2014;111:571-7.

31. Burrin DG, Ng K, Stoll B, Saenz De PM. Impact of new-generation lipid emulsions on cellular mechanisms of parenteral nutrition-associated liver disease. Adv Nutr 2014;5:82-91.

32. Corrales F, Alvarez L, Pajares MA, Ortiz P, Mato JM. Impairment of methionine metabolism in liver disease. Drug Investig 1992;4:8-13.

33. Deminice R, da Silva RP, Lamarre SG, et al. Creatine supplementation prevents the accumulation of fat in the livers of rats fed a high-fat diet. J Nutr 2011;141:1799-804. 